\title{
EDITORIAL
}

\section{Is Postevent Intravenous Hydration an Appropriate Service at Endurance Competitions?}

It has come to our attention that at least 3 businesses in Colorado have recently begun marketing postevent intravenous (IV) hydration services to athletes participating in endurance competitions, ${ }^{1}$ and other businesses scattered around the United States are doing the same. This practice is concerning because it tacitly encourages athletes to subscribe to a medical intervention that is generally unwarranted after endurance activity and with potentially deleterious consequences if performed without adequate medical screening and oversight. It is our opinion that the practice of providing postrace IV hydration services without understanding the potential consequences requires careful scrutiny and subsequent regulation before an athlete is harmed.

The administration of IV fluids without a firm medical indication is not new, but it seems to be expanding across some sports, both as a pre-event and postevent practice. $^{2,3}$ We first became aware of "for-purchase ondemand" IV services in 2011 before a large ultramarathon in Colorado. The race website posted an advertisement offering participants the opportunity to preorder a postrace IV hydration session at a cost of $\$ 75$ for the first liter of fluid and $\$ 25$ for the second liter. When one of us $(\mathrm{MDH})$ inquired of the medical director as to how athletes' safety would be ensured and that IV fluids would not be inappropriately administered to a hyponatremic athlete, risking significant worsening and possibly death from hyponatremia, the offer for the service was rapidly removed from the website. Now in 2015 , we note a reappearance and proliferation of businesses promoting fee-based postevent IV hydration in several states with no clear indication that prospective clients are informed of the potentially lethal consequences.

Historically, there has been considerable concern about impairments in performance from dehydration during prolonged exercise, ${ }^{4}$ but we now know that athletes can tolerate considerable dehydration without serious adverse health consequences. In fact, there is little scientific literature linking exercise-related dehydration to life-threatening conditions in fluid-supported endurance events, ${ }^{5}$ and dehydration up to $4 \%$ loss in body weight (and in some cases beyond) does not appear to have significant adverse effects on endurance performance under some circumstances. ${ }^{6-10}$ When athletes have access to fluids, severe levels of dehydration are rare, and when athletes do become dehydrated, oral rehydration is usually adequate and preferred. ${ }^{3,11}$ An exception is when dehydration is coupled with protracted nausea and vomiting. ${ }^{12}$ Recent consensus guidelines for medical care at ultraendurance events indicate that IV isotonic fluid infusion is appropriate (when available) if oral fluid intake is not tolerated and clear signs of hypovolemia (persistent tachycardia, poor skin turgor, and lightheadedness when standing) are evident. ${ }^{13}$ When an athlete is able to tolerate oral fluids, there is no justification for infusing IV fluids. Those few athletes who do require IV fluids should be thoroughly evaluated by competent medical staff who can monitor and assess the response to therapy as well as escalate care if needed. The practice of providing postrace IV hydration without medical assessment, without follow-up, and without utilization of accepted guidelines is inappropriate and also puts a burden of emergency response on the community emergency medical system.

Exercise-associated hyponatremia (EAH) has been found to be common in prolonged endurance events, with postrace incidents being as high as $51 \%$. $^{8,9,14}$ Fortunately, most EAH is asymptomatic and will selfcorrect if excessive fluid intake is avoided while this correction is allowed to occur. When symptomatic, the initial presentation often includes mild and nonspecific symptoms that can be easily dismissed or confused with other causes, including dehydration. However, symptoms can rapidly progress, even an hour or more after exercise is stopped, ${ }^{15}$ often presenting with prolonged seizure. ${ }^{15-19}$ If the underlying diagnosis of EAH encephalopathy is not promptly recognized and appropriately treated with hypertonic saline, death can result. Unfortunately, there have been several deaths related to EAH during various endurance activities and sports. ${ }^{14,20}$

Because the underlying pathophysiology of EAH involves the hormonal influences of arginine vasopressin causing water retention, ${ }^{14,20}$ the administration of isotonic or hypotonic fluids will further lower the serum sodium level in EAH, potentiating morbidity and mortality. ${ }^{21}$ EAH may also be associated with brain 
natriuretic peptide secretion, which can increase urine sodium losses, exacerbating already critically low sodium levels. ${ }^{22}$ For these reasons, additional isotonic or hypotonic fluids can worsen EAH or cause mildly symptomatic cases to worsen. ${ }^{21}$ Rather, proper initial treatment of EAH includes fluid restriction and oral hypertonic saline for mildly symptomatic cases, and emergent hypertonic saline infusion for more symptomatic cases. ${ }^{14,20}$ Clearly, thoughtful medical assessment is required to assure an athlete is not at risk from inappropriate postevent IV fluid infusions.

It is our understanding that postevent IV hydration business ventures in Colorado and elsewhere do not provide medical assessments for EAH. Nor do these ventures appear prepared to evaluate and appropriately manage rapid deterioration from EAH. As a result, the business model may inadvertently push athletes into potentially fatal situations. In the spirit of "first do no harm," we bring your attention to this potentially catastrophic practice. We are aware that a complaint has been made to the Colorado Medical Board and hope that the state will respond with appropriate oversight of these questionable ventures, and that other states will follow suit.

Martin D. Hoffman, MD

Department of Physical Medicine \& Rehabilitation

Department of Veterans Affairs, Northern California Health Care System and University of California Davis Medical Center, Sacramento, CA

Tamara Hew-Butler, DPM, PhD Exercise Science Program, Oakland University Rochester, MI

William O. Roberts, MD Department of Family Medicine and Community Health University of Minnesota, Minneapolis, MN

Ian R. Rogers, MD

Department of Emergency Medicine, St John of God Murdoch Hospital and University of Notre Dame Perth, Western Australia, Australia

Mitchell H. Rosner, MD

Division of Nephrology University of Virginia Health System Charlottesville, VA

\section{References}

1. Iannetta J. Endurance athletes turn to hydration by IV despite medical skepticism. The Denver Post. July 14,
2015. Available at: http://www.denverpost.com/lifestyles/ ci_28477931/endurance-athletes-turn-hydration-by-iv-de spite-medical. Accessed December 28, 2015.

2. Gesik NY, Tan SK, Prentiss GT, Fitzsimmons S, Nichols AW. The use of pregame hyperhydration with intravenous fluids in National Collegiate Athletic Association Football Bowl Subdivision teams. Clin J Sport Med. 2013;23:488-490.

3. van Rosendal SP, Osborne MA, Fassett RG. Lancashire B, Coombes JS. Intravenous versus oral rehydration in athletes. Sports Med. 2010;40:327-346.

4. Cheuvront SN, Kenefick RW. Dehydration: physiology, assessment, and performance effects. Compr Physiol. 2014;4:257-285

5. Noakes TD. Hyponatremia in distance athletes: pulling the IV on the 'dehydration myth.' Phys Sportsmed. 2000; 28:71-76.

6. Cheung SS, McGarr GW, Mallette MM, et al. Separate and combined effects of dehydration and thirst sensation on exercise performance in the heat. Scand J Med Sci Sports. 2015;25(suppl 1):104-111.

7. Goulet ED. Effect of exercise-induced dehydration on time-trial exercise performance: a meta-analysis. $\mathrm{Br} J$ Sports Med. 2011;45:1149-1156.

8. Hoffman MD, Hew-Butler T, Stuempfle KJ. Exerciseassociated hyponatremia and hydration status in 161-km ultramarathoners. Med Sci Sports Exerc. 2013;45:784-791.

9. Noakes TD, Sharwood K, Speedy D, et al. Three independent biological mechanisms cause exerciseassociated hyponatremia: evidence from 2,135 weighed competitive athletic performances. Proc Natl Acad Sci USA. 2005;102:18550-18555.

10. Wall BA, Watson G, Peiffer JJ, Abbiss CR, Siegel R, Laursen PB. Current hydration guidelines are erroneous: dehydration does not impair exercise performance in the heat. Br J Sports Med. 2015;49:1077-1083.

11. McGowan V, Hoffman MD. Characterization of medical care at the 161-km Western States Endurance Run. Wilderness Environ Med. 2015;26:29-35.

12. Hew-Butler T, Sharwood K, Boulter J, et al. Dysnatremia predicts a delayed recovery in collapsed ultramarathon runners. Clin J Sport Med. 2007;17:289-296.

13. Hoffman MD, Pasternak A, Rogers IR, et al. Medical services at ultra-endurance foot races in remote environments: medical issues and consensus guidelines. Sports Med. 2014;44:1055-1069.

14. Hew-Butler T, Rosner MH, Fowkes-Godek S, et al. Statement of the Third International Exercise-Associated Hyponatremia Consensus Development Conference, Carlsbad, California, 2015. Clin J Sport Med. 2015;25:303-320.

15. Hoffman MD, Stuempfle KJ, Sullivan K, Weiss RH. Exercise-associated hyponatremia with exertional rhabdomyolysis: importance of proper treatment. Clin Nephrol. 2015;83:235-242.

16. Davis DP, Videen JS, Marino A, et al. Exercise-associated hyponatremia in marathon runners: a two-year experience. J Emerg Med. 2001;21:47-57.

17. Pearce EA, Myers TM, Hoffman MD. Three cases of severe hyponatremia during a river run in Grand Canyon 
National Park. Wilderness Environ Med. 2015;26:189195.

18. Rogers IR, Grainger S, Nagree Y. Exercise-associated hyponatremic encephalopathy in an endurance open water swimmer. Wilderness Environ Med. 2015;26:59-61.

19. Zelingher J, Putterman C, Ilan Y, et al. Case series: hyponatremia associated with moderate exercise. Am J Med Sci. 1996;311:86-91.

20. Bennett BL, Hew-Butler T, Hoffman MD, Rogers IR, Rosner MH, Wilderness Medical Society, Wilderness
Medical Society practice guidelines for treatment of exercise-associated hyponatremia: 2014 update. Wilderness Environ Med. 2014;25(suppl 4):S30-S42.

21. Bennett BL, Hew-Butler T, Hoffman MD, Rogers IR, Rosner MH. In reply to clinical practice guidelines for treatment of exercise-associated hyponatremia. Wilderness Environ Med. 2013;24:468-471.

22. Harris G, Reid S, Sikaris K, McCrory P. Hyponatremia is associated with higher NT-proBNP than normonatremia after prolonged exercise. Clin J Sport Med. 2012;22:488-494. 